\title{
THE IMPACT OF AIRPORT SHOPPING ENVIRONMENTS AND DWELL TIME ON CONSUMER SPENDING
}

This article provides new insight into how the ambience and design of shopping environments impact onspending behaviour. Environmental cues in a retail area influence emotional states of by-passers, which in turn influence spending levels. Past research suggested that this effect only applies to shops with moderate arousal level. Also, several studies failed to confirm a relationship between emotions and spending levels. This is surprising, since high arousal environments (e.g., amusement parks, sports stadiums and airports) often feature a wide range of retail outlets. Based on survey data collected in a live airport shopping area, this study finds a relationship between pleasure emotions associated with the retail area and recalled consumer spending, but also the time available for shopping (which in an airport is constrained). Also, visitors' emotional state was influenced by the ambience (e.g., cleanliness, noise levels, lighting) as well as the design (e.g., easy wayfinding, seating areas) of the retail area. Shopper's arousal levels did not explain variations in spending level. Implications for researchers and managers are discussed as well as suggestions for future research.

Keywords: retail, airports, servicescapes, environmental psychology

The effect of physical stimuli of the environment on consumer behaviour has been proposed by environmental psychologists (Mehrabian - Russell, 1974) and introduced to retailing over 30 years ago (Donovan Rossiter, 1982). Pleasant ambience and appropriate design of shopping environments have been shown to cause approach behaviour. For example, pleasant ambient lighting in a store makes it appear friendly, welcoming, which attracts customers to the store or makes them stay longer then intended (Markin - Lillis - Narayana, 1976; Soars, 2009). Likewise, bright light has been linked to a higher level of arousal, as it causes a higher level of alertness and increases pulse and respiration (Mehrabian, 1976; Rook, 1987). Higher arousal, in turn, was shown to lead to a higher likelihood to interact with people in the environment (Summers - Hebert, 2001). Environmental cues don't affect behaviour directly, but impact a consumer's emotional state, which mediates the behavioural reaction of the consumer. Despite the fact that store designers have been applying this knowledge in store design since several years (Józsa - Bátor - Sassné
Grósz, 1999; Levy - Weitz, 2009), it has been noted that there are still a number of unanswered questions in this field of research (Ezeh - Harris, 2007).

The underlying model of environmental psychology assumes that moderate levels of arousal cause approach, and high or low arousal causes avoidance behaviour (Mehrabian - Russell, 1974). This poses the question why retail concepts set in high arousal environments (such as airports) can be successful, and if the model holds up in this industry, too. We have identified only few studies in this field, for example dealing with sports stadiums and amusement parks (Wakefield - Blodgett, 1999), and are not aware of any applications of the Mehrabian - Russell model (M-R) to airport environments in the past. The ideal ambience and design of stores may differ from industry to industry (Fodness - Murray, 2007), therefore many studies use general constructs of environmental cues (for example, information load of the environment). Some studies discuss specific factors, such as music and smell (Spangenberg, Grohmann, - Sprott, 2005) and exclude other factors. We will therefore discuss the effects of eight 
types of environmental cues considered relevant for the retail setting. The output variable applied in most studies is 'approach-avoidance', an eight-item construct measuring a wide range of concepts including intention to spend time in a store, satisfaction, recommendation to others and communication with others while in the store (Donovan - Rossiter, 1982), or solely total time spent in an environment (Levy - Weitz, 2009; Wakefield - Baker, 1998). However, investment into costly redesign of stores and a unique ambience, the impact on consumer spending is a more relevant measure then approach behaviour (Spangenberg - Sprott - Grohmann - Tracy, 2006). We therefore apply consumer spending as an output measure.

We aim to answer the following research questions: What are the main environmental cues influencing consumers' emotions in a time pressured, high arousal environment? Does available time for shopping influence emotions? What is the impact of pleasure, arousal and available time for shopping on consumer spending?

This paper reports results of two studies conducted at a major European airport. Findings establish a relationship between the ambiance and design of the retail area and passenger's emotional states (study 1), as well as the effect of emotions on consumer spending at the airport's shops (study 2). The next section on theoretical background focuses on the M-R model, which is the underlying concept of this approach, and introduces the reader to the airport retailing industry. Then we present the conceptual framework, define the constructs used, and develop the hypotheses to be tested, followed by the operationalization of variables. We then present, in turn, the methodology and results of studies 1 and 2 . We then discuss results in detail, followed by limitations and indications for further research, as well as managerial implications.

\section{Theoretical background}

The M-R model assumes a Stimulus-Organism-Response taxonomy, where the environment (stimulus) has an impact on the emotional states of consumers along three dimensions, pleasure, arousal or dominance (organism). The model has been widely applied in service industries (see Turley - Milliman, 2000 for an overview), with environments often being referred to as 'servicescapes', meaning "all of the $o b$ jective physical factors that can be controlled by the firm to enhance (or constrain) employee and customer actions" (Bitner, 1992: p. 65.). While the list of possible factors is long (see Baker, 1987; Bitner, 1992, for two alternative overviews), most research has concentrated on only a few ones, including noise and music (Baker - Levy - Grewal, 1992; Hui - Dubé Chebat, 1997; Milliman, 1982; Yalch - Spangenberg, 1990), scent (Mattila - Wirtz, 2001; Spangenberg Crowley - Henderson, 1996), ambient temperature (d'Astous, 2000; Wakefield - Baker, 1998), cleanliness (d'Astous, 2000), store lightning (Summers - Hebert, 2001), store layout (Hasty - Reardon, 1996; Levy - Weitz, 2009), colours, materials and decor (Wakefield - Baker, 1998).

The definition of emotions assumes that they are a short termed affect, a "mental state of readiness that arises from a cognitive appraisal of events or thoughts" (Bagozzi - Gopinath - Nyer, 1999: p. 184.). They are shorter, lasting from several minutes to a few hours at most, whereas moods last from several hours to days. Emotions are more strongly linked to physiological changes then general moods (Bagozzi et al., 1999). Changes to emotions can be triggered if a situations occurs which, for example, puts an important personal goal at risk, such as catching a plane. The M-R model measures emotions with three distinct dimensions, where the pleasure dimension refers to being happy, joyful, or satisfied in the specific environment, arousal refers to feelings of being active, excited, alert at that moment, and dominance is attributed to a feeling of being in control and having freedom to act. The three constructs were developed in an attempt to cover all relevant emotional reaction to the environment, are claimed to be orthogonal (Donovan - Rossiter, 1982). There has been some criticism about dominance having low explanatory power, and many studies indeed apply the M-R model without the dominance dimension (Russell - Pratt, 1980; Russell - Weiss - Mendelsohn, 1989).

Several studies have shown that pleasure can cause customers to approach a retail environment, and included willingness to spend money as part of an approach construct (Donovan - Rossiter, 1982; Hui Bateson, 1991). People in a positive mood likely to make a higher number of purchases because of reduced decision time when in a positive mood (Isen, 1987). Secondly, if their pleasure feelings is being attributed to the experience in a particular store, they are more likely to reward the store by doing business with them, even if in the form of a small purchase (Babin - Darden, 1996). However, there are few studies which were able to confirm these relationship in retail settings. One study identified a relationship between pleasure and unplanned spending but no influence of arousal. In unpleasant environments, emotions did not influence unplanned spending (Donovan - Ros- 
siter, 1982). Another study conducted in a mall, found that positive moods influence satisfaction, but not consumer spending (Babin - Darden, 1996). Another study in a Canadian mall resulted in a significant but very weak link between pleasure and shopper's spending (Beta=-.02) (Chebat - Michon, 2003). Slow paced music was shown to lead to higher total sales, because shoppers move at a the lower pace and are more likely to find produce they are looking for or to notice and react to in-store promotions, for example (Milliman, 1982).

It is widely accepted that the environment also has cognitive effects on consumer behaviour. Cognitive effects include all of the thought processes in a consumer's mind, which involve the collection, processing, storing and recalling of information. For example attitude towards a retail concept has shown to influence consumer behaviour (Ajzen - Fishbein, 1977). The study presented here uses data collected in an airport retail environment, and previous research showed that emotions have a far greater explanatory power of behaviour in this specific retail concept (Volkova, 2009).

Major international airports are nothing short of shopping malls: London's Heathrow Airport, for example, comprises of $66,000 \mathrm{sqm}$ of retail space, and it's commercial area exceeds 1 billion USD sales per year (Baier, 2010). In 2010, sales per square meter at the largest European airports exceeded 34,000 USD/ sqm (Rimmer, 2011), while major shopping centres in Germany, for example, generate between 10,000 and 30,000 USD/sqm annually (Liermann - Rumetsch, 2011). Recently, many airports have focused more on retail operations to deliver additional revenues, while traditionally the majority of income was generated by charging for use of infrastructure by airplanes and passengers (aeronautical revenues). Pressure to grow nonaeronautical revenues (such as revenues from leasing out or operating retail outlets) has been increasing since airlines are less and less ready to pay high airport charges in an increasing competitive market for travel (Graham, 2009), and also with continues cost increases for security and other regulatory and legal requirements (Thompson, 2007).

Passengers mostly browse duty free shops 'to fill in time' and only secondly 'to find a particular product' (Baron - Wass, 1996). Therefore, having sufficient dwell time in the retail area has a high influence on likelihood to buy (Freathy - Connell, 2012; Torres Dominguez - Valdes - Aza, 2005). It is understood that the majority of airport shopping is done on impulse (Crawford - Melewar, 2003; Omar, 2001), with the strength of the impulse effect being largely driven by the psychological effects of the airport experience (Volkova, 2009). Thomas (1997) identified two emotional anomalities: Firstly, stress levels are increased because customers are out of their daily routine. Secondly, she notes an increase in levels of anticipation and excitement. The research shows that passenger's stress levels reduce when they receive their boarding pass, but excitement remains high. This period is referred to as 'happy hour' by managers, and airport retailers are mainly concerned with manipulating this period of passenger excitement (Thomas, 1997).

\section{Conceptualisation and construct definitions}

The conceptual framework we propose is grounded in the M-R model, and assumes that the airport's servicescape influences passengers' emotions, and - in turn - emotions have a direct effect on spending. While each passenger will pass a number of the stores in the retail area and may become a customer, his or her primary goal is to reach his departure gate, and he may not have considered shopping as a means to spend the waiting time. Airport infrastructure is often designed to enable large volumes of passengers to pass passenger security screening and passport control, and to find their way to the gate on time in order to allow a punctual departure. Passengers are also aware and conscious of the need to complete a formal process, and any uncertainty or delay in completing this represents a risk to achieving the goal of travelling.

From a psychological perspective, the danger of not accomplishing this important objective may cause acute stress and other forms of trait anxiety, which is manifested by physiological signs, such as faster heart rates, higher blood pressure. Passengers are highly aroused and may be looking for ways to overcome the objectives, such as a long queue in front of them, asking for help from airport personnel or other forms of coping with the situation. At the same time, however, many people in airports do also experience feelings of excitement, for example the anticipation of an upcoming holiday, the joy of returning home after long travels, or pride of bringing home a signed business deal. For many airport users, air travel may still be considered as something exclusive, extraordinary, and the airport atmosphere could be described as being 'special'.

We therefore propose that the characteristics of the airport environment as perceived by the passenger have an effect on the emotions being attributed to that environment (see Figure 1). This study focuses on two groups of servicescapes, ambient factors and design factors, where ambient factors include items which in- 
Conceptual framework: The airport environment's impact on retail spending

Figure 1

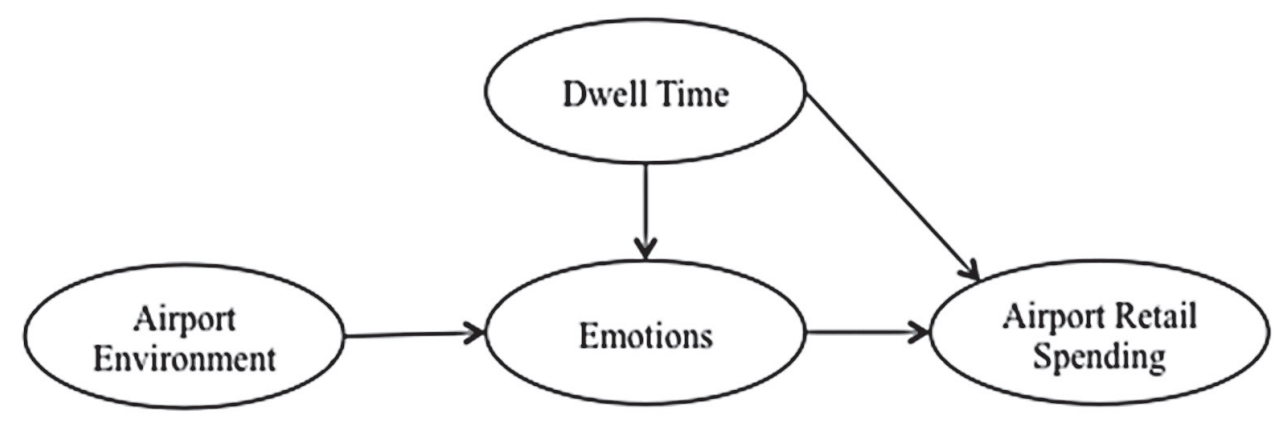

fluence feelings unconsciously, such as music or light, and design factors are more noticeable, such as presence of signage and store layout. The conceptual framework contains only self-reported measures, which were taken at the exit of the main retail zone to minimize memory effects. We define airport environment as all of the physical factors of an airport's retail area, that can be influenced to enhance (or constrain) customer actions, as reported by passengers when leaving.

The construct of emotions used here contains the emotions perceived as being characteristic of the retail environment, to ensure that respondents consider affect influenced by the environment rather than other events or situations in their life. The emotions measures are the affect associated with the retail environment, as reported by passengers when leaving. Conceptually, emotions will be handled as constructs representing the two main dimensions pleasure and arousal, based on the M-R model. There is widespread evidence that the dominance factor ads little explanatory value (Bagozzi et al., 1999; Donovan - Rossiter, 1982; Russell - Pratt, 1980) and we propose to use only the two factors pleasantness, and arousal/activation/engagement (Watson Tellegen, 1985). They have been suggested to be orthogonal, although not wholly independent from each other (Russell - Pratt, 1980; Russell et al., 1989). In an environment of neither pleasure nor displeasure, moderate arousal causes approach, and high or low arousal causes avoidance behaviour. In a pleasant environment, a higher arousal will lead to higher likelihood of approach (Mehrabian - Russell, 1974). A detailed investigation of the interaction effects is out of scope of this paper, because the study is limited to a single environment. Most applications of the M-R model use rather lengthy scales to measure pleasure/arousal, for example Mehrabian and Russell (1974) and Donovan, Rossiter, Marcoolyn, and Nesdale (1994) used 18 items in their original scale, which could lead to respondent fatigue. This study aims at using fewer items to measure emo- tions, but, following the recommendation of Bagozzi (1999) to have no less than three items by subcategory.

To discuss the relationship between airport environments and emotions, we reviewed past studies into shopping mall interiors. Aural factors - especially music - has been widely studied, and is assumed to influence both pleasure and arousal, however the effect is highly related to the congruency with the brand and store image, as well as consumer preference for the music played (Dubé - Chebat - Morin, 1995; Sweeney Wyber, 2002; Yalch - Spangenberg, 1990). It has also been suggested that the presence of unpleasant sound ('noise') is irritating customers (d'Astous, 2000) and negatively influences pleasure and arousal (Dubé et al., 1995). Shopping malls may chose not to play music to reduce presence of disturbing sounds (Soars, 2009). Cleanliness has been found to be an important factor of the environment in shopping centers (Oppewal - Timmermans, 1999; Wakefield - Blodgett, 1999), travel agencies (Bitner, 1990) as well as railway systems (Cheng, 2010) and was shown to positively influence emotions (Wakefield - Blodgett, 1999). We phrase the item 'clean and tidy' to avoid misunderstandings to be clean smells (Ward - Davies - Kooijman, 2007), and specifically refer to cleanliness as an absence of dirt and clutter on the floor (Bitner, 1990). Finally, bright lighting causes more examination and handling of merchandise in shops (Areni - Kim, 1994; Summers - Hebert, 2001), and lead to a higher level of arousal (Mehrabian, 1976; Rook, 1987). Softer light may cause shoppers to slow down, reduce levels of arousal and cause positive emotions (Markin, et al., 1976; Soars, 2009). In summary, we propose to measure the ambience of an airport's shopping area using items quiet, clean and tidy and well-lit. Environments for which these were found to be more characteristic are hypothised to positively influence consumer emotions.

Dwell time in a retail area of an airport are an important determinant of airport sales (Freathy - O'Connell, 
2012), and are included in the conceptual framework as a construct that has an effect on both consumer spending and emotions. Dwell time is the consumer's time spent in an area featuring shops and restaurants, as reported by the consumer on exit. In most airports, this area is physically located behind security screening, and before the boarding areas, where passengers queue up to board their plane. For lack of objective time measurements, dwell time is a self-reported measure, taken immediately at the exit of this area. While the change of behaviour in a shopping mall over time has been discussed before (Areni - Kim, 1994) the effect of dwell time on spending is an under researched area. This may be because the time spend for shopping is usually controlled by the shopper and therefore rather an output measure. Longer time spent could be caused by a satisfactory shopping experience, a pleasing environment, or even a long shopping list. At airports, however, passengers are urged to enter the closed zone between security and their departure gate as early as possible, which not surprisingly features most retail outlets and restaurants.

Passenger dwell time in the retail area has a high influence on their likelihood to buy something and total expenditure (Freathy - Connell, 2012; Torres, et al., 2005), partly because the likelihood for impulse shopping increases with the number of products and offers customers look at(Omar, 2001), but also because shopping can be an activity done to 'kill time'(Crawford - Melewar, 2003). Furthermore, planned airport shopping could be postponed in case of lack of time. Dwell time could also have a mediating effect on consumer emotions, for example when it is shorter than the time necessary, leading to time pressure. We discussed earlier, that negative arousal may occur when someone appraises the available time to be too short to comfortable reach the departure gate, and the goal of travelling is under threat. One may argue that the level of arousal increases with time available decreasing, with the effect being 'zero' when time is perceived to be well sufficient. Dwell time and time available before boarding are highly correlated (the difference is the time spent in the departure gate, which we assume to be constant). We therefore argue that dwell time has a negative effect on arousal.

The output measure of the framework is consumer spending, which is defined as the total amount spent by an individual in all retail units visited during that shopping trip, as reported at the exit. This measure allows us to estimate total airport retail sales per passengers in the study. Several studies have confirmed the link between emotional states of shoppers and consumer spending.
Consumers responding positively to the retail environment, and feeling happy or satisfied will want to spend more time in the environment, want to look around and interact with other individuals present (Mehrabian Russell, 1974). For example, consumers with higher levels of self-reported pleasure as a result of ambient music have shown higher spending levels (Caldwell - Hibbert, 2002). Only few studies based on the M-R model have used spending as output measure (Babin Darden, 1996; Milliman, 1982), most use more general, multi-item constructs, such as approach-arousal or store patronage (Chebat - Michon, 2003; Donovan - Rossiter, 1982; Donovan et al., 1994). It has been argued that the effect of environmental cues on sales is significantly weaker than their effect on approach (Donovan et al., 1994), which also may explain the reason for the lack of usage. However the commercial performance of airport retail operations is generally assessed based on spending related measures, such as sales per square meter, or share of non-aeronautical sales of the total revenue (Doganis, 1992; Humphreys - Francis, 2002; Torres et al., 2005), giving studies with sales as the dependent variable a higher relevance.

\section{Operationalization of variables}

Based on the conceptual framework, two separate measurement models were developed and tested with personal quantitative survey based on customer interviews. The first model analyses the effect of eight environmental variables on emotions, namely pleasure and arousal (see Figure 2), while the second one deals with the effect of emotions on consumer spending (see Figure 3). We will now in turn discuss how each of the variables were operationalized and then propose the hypothesis to be tested in the two studies.

The items measuring ambience and design of airport retail environments were selected based on past studies and adopted to fit the environment if necessary. Consumers were asked how characteristic eight expressions of the airport's retail zone were close to the exit of the area, on a seven-point Likert scale from "not at all" to "very characteristic". The expressions related to airport ambience were clean and tidy (Ward et al., 2007), noisy (d'Astous, 2000), well-lit (Mehrabian, 1976; Rook, 1987). In addition to these, several authors (Thomas, 1997; Volkova, 2009) have noted a certain excitement and anticipation of the air travel ahead, which in part is being triggered by the environment. Airports are unique environments and one could argue that they have a special atmosphere to most people, being exclusive areas or at least nothing ordinary. In order to capture this aspect, 
we included the item special atmosphere. Further items, related to the design and layout of the building, were adequate number of seats (Wakefield - Blodgett, 1999); easy to find your way (Hui - Bateson, 1991); Exciting colours (Chebat - Morrin, 2007). Finally, based on a measure for organisation of merchandise in shopping facilities (Baker - Parasuraman - Grewal - Voss, 2002), we included the item well-arranged areas to cover aspects of merchandise and stores being easy to find but also layout of the facility to be easy to understand and overlook. The order of items was randomly scrambled before each interview and one item was reverse coded (noisy). spondents were asked to recall the amounts spent for each individual store visited in turn, and then summed up to calculate "recalled spend" in Euro. Most customers are able to correctly recall prices after purchase (Gabor - Granger, 1961; Wakefield - Inman, 1993), nonetheless, the lack of an actual measure is a minor limitation of the study (Monroe - Lee, 1999).

\section{Relationship of Environment and Emotions}

Cleanliness has been linked to consumer's positive evaluation in shopping environments (Oppewal -Timmermans, 1999; Wakefield - Blodgett, 1999) and railway systems (Cheng, 2010). Dirt and clutter on the

\section{Measurement model (Study 1)}

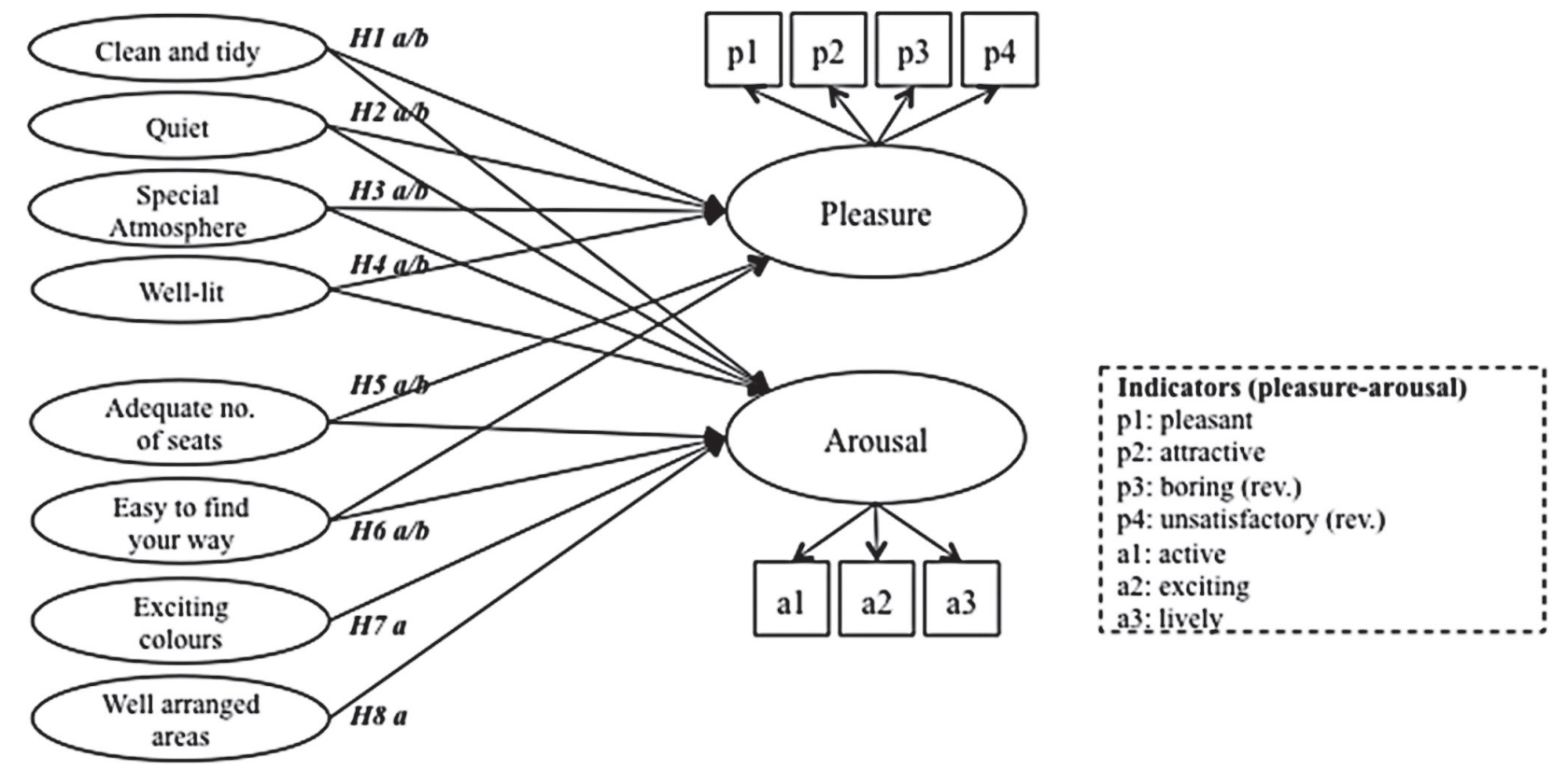

Emotional measures are shortened versions of measures proposed by Donovan and Rossiter (1982) and Bitner (1990) were adjusted to fit the airport environment (Omar, 2001; Perng - Chow - Liao, 2010). Respondents were asked to assess which emotional characteristics they would use in relation to the retail area, and to assign a score of 1- not at all characteristic to 7-very characteristic to the expressions pleasant, attractive, boring, and unsatisfactory. The latter two were reverse scored for variety. The measure pleasure was computed as the average score of these four. Equally, arousal is the average of the scores given for active, exciting, lively (see Table 1).

Perceived dwell time was measured by asking respondents how many minutes they did spend "in the area between security check and the gates, which is equipped with shopping and restaurant facilities." Re- floor has been shown to lead to lower levels of pleasure (Bitner, 1990) and may upset or anger customers thus increasing arousal. We therefore state that:

Hypothesis 1a/b: Customer perception of an airport's cleanliness and tidiness increases pleasure (a) and reduces arousal (b).

Noise in shopping centers is irritating customers (d'Astous, 2000) and negatively influences emotions (Dubé et al., 1995). There has also been extensive research into the effects of music on pleasure and arousal (Dubé et al., 1995; Sweeney - Wyber, 2002; Yalch Spangenberg, 1990). Sounds influence people's feelings towards the respective area, with pleasant sounds leading to more positive evaluations. Noisy environments are likely to be arousing and activating, as people prepare to leave the area as soon as possible. We therefore propose: 
Hypothesis 2a/b: Customer perception of an airport's quietness increases pleasure (a) and reduces arousal (b).

Qualitative research conducted by the author has shown that airport environments are considered special and exciting by most shoppers, in a similar way as air travel is exciting (Bohl, 2013). We hypothise that this 'special atmosphere' will lead to feelings of happiness and also reduce any anxiety or fears which may have been present during the formal processing (i.e., security screening):

Hypothesis 3a/b: Customer perception of an airport's special atmosphere increases pleasure (a) and reduces arousal (b).

Lightning has been shown to influence shopper feelings. Bright lighting can activate shoppers (Mehrabian, 1976; Rook, 1987), and prompts them to handle more merchandise inside shops (Areni - Kim, 1994; Summers - Hebert, 2001). Softer light may cause shoppers to slow down, reduce levels of arousal. Appropriate lightning can cause positive emotions (Markin et al., 1976; Soars, 2009). We therefore propose that:

Hypothesis 4a/b: Customer perception of an airport being well lit increases pleasure (a) and increases arousal (b).

Sufficient seating available near the retail areas may be required to allow people to stop in their ways, relax, and orient themselves. Comfort facilitates a higher effect of other atmospheric cues on pleasure (Ballantine - Jack - Parsons, 2010). Customers noticing and valuing large sitting areas are likely to be more passive. Therefore:

Hypothesis 5a/b: Customer perception of an airport having an adequate number of seats increases pleasure (a) and reduces arousal (b).

The design of terminal interiors will influence the ability for people to find their way, for example to the appropriate departure gate. Travel is the main objective of their presence in the airport, negative feelings (such as unhappiness) may be caused if they are unable to orientate themselves, or unaware of walking distances inside the terminal (Thomas-Emberson, 2007). It may also be argued that uncertainty about where to go can lead to passiveness, for example people may be expected to sit down and wait for new announcements or a flight display to show their departure gate. This would mean a negative effect on arousal, and we propose that:

Hypothesis 6a/b: Customer perception ease to find your way in an airport increases pleasure (a) and increases arousal (b).
Colour schemes have been found to have physiological influence on people, with liked colours causing pleasure, and bright, activating colours increasing heart rate, conductance of skin and respiratory rate (Bellizzi Crowley - Hasty, 1983). To ensure that liking of colour interferes with responses, we explicitly postulate that exciting colours have an activating effect on consumers:

Hypothesis 7a: Customer perception of an airport featuring exciting colours increases arousal.

Fodness and Dale (2007) identified 'effectiveness' to be very important to airport customers, a variable which had high scores when the terminal building featured well-arranged areas. Retail zones featuring a logical lay-out, following passenger flow, with high visibility (low shelves, for example), are likely to be encourage more people to explore the stores and interact with sales personnel. We argue that:

Hypothesis 8a: Customer perception of an airport featuring well-arranged areas increases arousal.

Positive feelings associated with a store are likely to result in a more beneficial assessment of the retail offering. Consequently, previous studies in shopping malls found pleasure and spending to be weakly related to each other (e.g., Chebat - Michon, 2003). The effect of pleasure is likely to be particularly strong on unplanned spending (Donovan et al., 1994). Because the majority of airport shopping is done on impulse (Omar, 2001), we propose:

Hypothesis 9: Pleasure has a positive effect on recalled spending in retail outlets.

Arousal is a state of readiness which increases the mind's ability to acquire, retrieve, digest and interpret information. If arousal is too high, however, this ability reduces and cognitive and information processing slows down (Groeppel-Klein, 2005). While arousal has been found to mediate the effect of pleasure on spending (Donovan - Rossiter, 1982), several studies found only a small (Babin - Darden - Babin, 1998) or no effect (Donovan et al., 1994) on spending levels. We argue that this could be because in normal shopping situations, only average levels of arousal are reached, with no effect on spending. The (negative) arousal caused by airport security processes and anxiety related to possible delays or flying itself could, however, lead to lower spending. We therefore argue that:

Hypothesis 10: Arousal has a negative effect on recalled spending in retail outlets.

Time constraints during shopping (which in airports are given by the boarding time of a flight) may have an 
effect on emotions. A lack of time would cause people to feel time pressure (Bowes, 1998). Having 'free' time before the trip unexpectedly may cause feelings of satisfaction (i.e., pleasure), which is likely to be higher the more time is available.

Hypothesis 11: Longer perceived dwell time in the airport's retail area has a positive effect on pleasure

Airports are unique retail environments with customers being a captive audience while they are waiting for their flight. Also being called the 'happy hour' (Thomas, 1997) the likelihood for passengers to buy on impulse during that period has been reported to be as high as 70\% (Omar, 2001). Most purchases are done in order to 'kill time' (Crawford - Melewar, 2003). Time pressure, on the other hand, reduces the likelihood for impulse purchases and reduces sales (Iyer, 1989). A linear positive relationship between the duration customers spend in the retail area ('dwell time') and sales has been shown in previous studies (Madeira, 2011).

Hypothesis 12: A longer perceived dwell time in the airport's retail area has a positive effect on recalled consumer spending. any of the airports shops. Passengers were intercepted near the exit of the retail area from 5am to 9pm, equally spread over each day of the week. In total 977 questionnaires were useable, all participants gave informed consent, participation was voluntary and no reward was offered. $41 \%$ of the respondents were male, $69 \%$ between 18 and 45 years, $93 \%$ between 18 and 65 years, $87 \%$ local nationals, and $13 \%$ from other countries. $41 \%$ visited a shop in the terminal, of which $69 \%$ made a purchase. $41.1 \%$ of the respondents entered a shop, and $28.7 \%$ purchased something.

To verify that the emotional measures represent the intended two dimensions, we conducted a confirmatory factor analysis on the data set obtained in study two $(n=315)$. We used the factor analysis function of SPSS v.20, applied a Varimax rotation to the initial solution, and found results to be satisfactory (see Table 1): All items had rotated factor loadings of 0.50 or greater (Hair - Anderson - Tatham - Black, 1998), and communalities of the items were .63 or higher. The KaiserMeyer-Olkin Measure of sampling adequacy was .763, the approximate Chi-Square 2686.753 with 21 degrees of freedom (significant at $\mathrm{p}<.001$ ). The mean values are 6.146 for pleasure and 4.116 for arousal.

Table 1

Emotional constructs

\begin{tabular}{|c|c|c|c|}
\hline Emotional state (Factor) & Indicator & Factor loading & Variance explained (\%) \\
\hline Total & & & 67.333 \\
\hline \multirow{3}{*}{ Pleasure $(\mathrm{m}=6.146)$} & Pleasant & .792 & 44.327 \\
\cline { 2 - 4 } & Attractive & .827 & \\
\cline { 2 - 4 } & Boring $^{*}$ & .807 & \\
\cline { 2 - 4 } & Unsatisfactory $^{*}$ & .829 & 23.006 \\
\hline \multirow{3}{*}{ Arousal $(\mathrm{m}=4.116)$} & Active & .796 & \\
\cline { 2 - 4 } & Exciting & .777 & \\
\cline { 2 - 4 } & Lively & .842 & \\
\hline
\end{tabular}

* reverse coded

\section{Study 1 - Methodology and Results}

To test the above hypotheses, interviews were conducted with customers in a live airport retail environment from May to December 2012. Both studies reported here consist of convenience samples taken by intercepting people when leaving the airport's retail area. Although not representative for the total population, the findings will most likely include important and valuable insights because sample size is large. Participation for study 1 was open to all passengers being native speakers of English or Hungarian while study 2 also required participants to have purchased something in
Next a linear regression was run with pleasure as the dependent variable in order to test hypothesis $\mathrm{H} 1 \mathrm{a}$ to H6a. An adjusted R square of .319 suggests that the model explains a satisfactory share of the variations in pleasure. The data suggests no presence of multicollinearity, as VIF values are low (between 1.2 and 2.9). To verify linearity, we also ran a quadratic regression, which in the case of four variables had a good fit with slightly higher $\mathrm{R}$ square values $(\mathrm{p}<.001)$ then the linear regression. Cubic regression had a poorer fit. An examination of plots of the data and estimates revealed that quadratic and linear equations provided nearly identical estimates for pleasure being 4 or higher, but differed for values of 3 or lower. However, only $1.3 \%$ of 
the respondents gave scores of 3 or lower (m: 6.075, sd: .886, median: 6.250). We therefore continue our analysis based on a linear model. We reviewed the pearson correlation matrix of the independent variables in order to analyse the interactions and evaluate the fit of the model. Clean and tidy correlated stronger with well-lit (pearson correlation $=.461$ ) and easy to find your way $(.437)$. Finding ones way in an area is likely to be easier if it is appropriately lit and maybe if it appears clean and less cluttered. Although the correlation is still less than 0.5 , and each variable still adds unique value, their relatively high Beta values need to be interpreted with care. Welllit also correlates somewhat with adequate number of seats (.401). One should, however, consider that subconsciously the environmental cues perceived by customers have subconscious effects on them and can probably not always be accurately differentiated by respondents. All other correlation coefficients were below .4. We consider the values as acceptable for the purposes of this study but care needs to be taken when interpreting results as several variables are reinforcing each other's effect. tively low coefficient ( $\beta=.107$ ), and considering that this item also has a high correlation with at least two other variables, well-lit and well-arranged area, it adds limited value. It should be noted that the significance level for 'well-arranged areas' is relatively low, and the Beta coefficient not very small, suggesting that there may be some unexpected negative correlation with pleasure. Reasons for this could be that this measure has not been formulated exactly enough, as there are various areas in the retail area, such as seating areas outside the shops, and the shop interiors. It could be understood to refer to the terminal area outside the shops, which has a very open clear structure with many signs and displays and very easy way finding, but also respondents could have referred to individual shops where they have spent a lot of time, and may have considered the easiness of finding a certain category in the shop to be meant here. The variables age and dwell time were not shown to have a significant effect. Gender had a minor effect on pleasure, with a probability of $\mathrm{p}<0.05$ but with a relatively small explanatory power $(\beta=-0.051)$.

Table 2

The effect of airport retail environments on consumer emotions (study 1)

\begin{tabular}{|c|c|c|c|c|}
\hline Hypothesis & Effect (direction) & Beta (std.) & t-value & Hyp. accepted \\
\hline H1a & Clean and tidy $\rightarrow$ Pl. $(+)$ & .230 & $8.030^{* * * *}$ & yes \\
\hline $\mathrm{H} 2 \mathrm{a}$ & Quiet $\rightarrow$ Pl. (+) & .241 & $9.073^{* * *}$ & yes \\
\hline $\mathrm{H} 3 \mathrm{a}$ & Special atmo. $\rightarrow$ Pl. $(+)$ & .140 & $5.711^{* * *}$ & yes \\
\hline $\mathrm{H} 4 \mathrm{a}$ & Well-lit $\rightarrow$ Pl. $(+)$ & .217 & $7.715^{* * *}$ & yes \\
\hline $\mathrm{H} 5 \mathrm{a}$ & No. of seats $\rightarrow$ Pl. (+) & -.055 & $-2.269^{*}$ & no \\
\hline H6a & Easy wayfinding $\rightarrow$ Pl. $(+)$ & .178 & $6.313^{* * *}$ & yes \\
\hline $\mathrm{H} 1 \mathrm{~b}$ & Clean and tidy $\rightarrow$ Ar. $(-)$ & -.120 & $-3.568^{* * *}$ & yes \\
\hline $\mathrm{H} 2 \mathrm{~b}$ & Quiet $\rightarrow$ Ar. (-) & -.171 & $-5.479^{* * *}$ & yes \\
\hline $\mathrm{H} 3 \mathrm{~b}$ & Special atmo. $\rightarrow$ Ar. $(-)$ & .069 & $2.308^{*}$ & no \\
\hline $\mathrm{H} 4 \mathrm{~b}$ & Well-lit $\rightarrow$ Ar. $(+)$ & -.077 & $-2.323^{*}$ & no \\
\hline $\mathrm{H} 5 \mathrm{~b}$ & No. of seats $\rightarrow$ Ar. $(-)$ & .119 & $4.134^{* * *}$ & yes \\
\hline $\mathrm{H} 6 \mathrm{~b}$ & Easy wayfinding $\rightarrow$ Ar. $(+)$ & .071 & $2.178^{*}$ & no \\
\hline $\mathrm{H} 7 \mathrm{a}$ & Exciting colours $\rightarrow$ Ar. $(+)$ & .390 & $13.487^{* * *}$ & yes \\
\hline $\mathrm{H} 8 \mathrm{a}$ & Well arr. area $\rightarrow$ Ar. $(+)$ & -.082 & $-2.504^{*}$ & no \\
\hline
\end{tabular}

n=977, Pl.: Pleasure, Ar.: Arousal, ${ }^{*} \mathrm{p}<0.05,{ }^{* *} \mathrm{p}<0.01,{ }^{* * *} \mathrm{p}<0.001$

All variables hypothised to impact on pleasure were significant at the $\mathrm{p}<.001$ level (except adequate number of seats: $\mathrm{p}<.01$ ), therefore supporting hypotheses $\mathrm{H} 1 \mathrm{a}$, H2a, H3a, H4a, H5a and H6a (see Table 2). Cleanliness and tidiness $(\beta=.227)$ as well as quietness $(\beta=.220)$ have the highest influence on pleasure, followed by lighting $(\beta=.191)$, easyway-finding $(\beta=.178)$ and Special atmosphere $(\beta=.149)$. Adequate number of seats has a rela-
A separate linear regression with all environmental variables hypothised to influence arousal, as well as gender and age as control variables was run next. Following the same procedure to check for multicollinearity and non-linearity, we found data to be appropriate and continued with a linear model. $\mathrm{R}$ square was only .305 suggesting a lower explanatory value $(\mathrm{F}=53.037$, $\mathrm{df}=973, \mathrm{p}<.001)$. Age, gender and dwell time were not found to influence the dependent variable. Colours and well-arranged areas had the highest influence on arous-

\section{VEZETÉSTUDOMÁNY}


al, with coefficients of .320 and .259 respectively as a significance level of $\mathrm{p}<.001$. Cleanliness and quietness have a negative effect on arousal $(\beta=-.128 /-.178)$, i.e. are leading to a more passive, non-aroused state. These two items have the most strong positive influence on pleasure, and a combination of high pleasure and high arousal can be interpreted as a state of calmness, relaxation (Russell - Pratt, 1980; Russell et al., 1989). These four relationships were significant at a level of $p<.001$, and we can accept H1b, H2b, H7a and H8a. Special atmosphere, adequate number of seats, and easy to find your way did not show a significant relationship to arousal levels of the respondents, therefore we reject $\mathrm{H} 3 \mathrm{~b}, \mathrm{H} 5 \mathrm{~b}$ and H6b. Well-lit has shown a significant correlation with arousal at the $\mathrm{p}<.005$ level, however it has a negative coefficient of $\beta=-.095$ while we hypothised a positive relationship. This was based on the assumption that bright (soft) light will cause arousal (non-arousal). Maybe, a large number of respondents interpreted the item well-lit to mean soft, friendly, warm lighting, which has been shown to reduce arousal (Soars, 2009). We reject H4b and suggest rephrasing this item in future studies. (Figure 3)

\section{Measurement model (Study 2)}

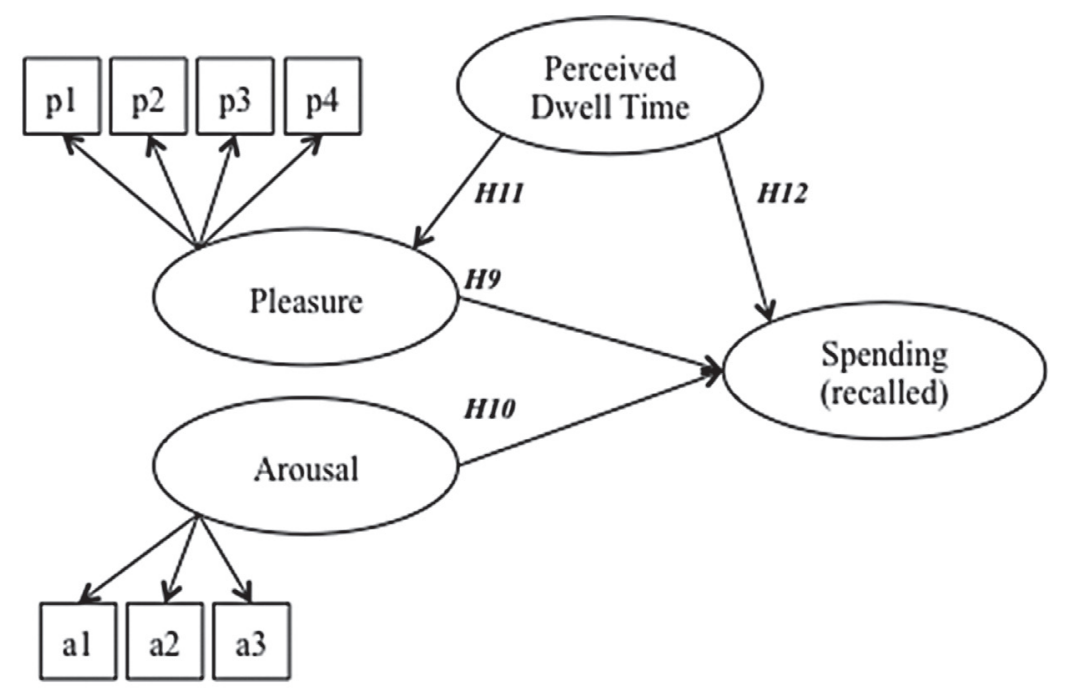

\section{Study 2 - Methodology and Results}

The data for study $2(n=315)$ was a subset of study 1 data, which contained only participants, who had purchased something in any of the retail shops on the same day. $37 \%$ of the respondents were male, $81 \%$ between 18 and $55 \%, 52 \%$ were at the beginning of a trip while $48 \%$ were returning home. This composition is similar to the overall population. Reliability of all measures was re-confirmed after the subset had been selected, and Cronbach's alpha values either stayed the same or improved. The pleasure measures showed effects on recalled spending levels $(\beta=.150, p<.05)$ therefore we can accept H9 (see Table 3). The effect of arousal however was not significant, and H10 needs to be rejected. H11 was tested by running a linear regression with the dependent variable being pleasure and independent variables being all environmental variables hypothised to be influencing pleasure (clean and tidy, and so on) as well as dwell time. We used the study 2 dataset (all shoppers, $\mathrm{n}=315$ ) and found no significant effect of dwell time on pleasure while all other relationships remained as reported earlier. Finally, dwell time was Figure 3 shown to have a significant effect on retail spending $(\beta=+.126, p<.01)$ and therefore H12 can be confirmed.

\section{Findings and Conclusion}

The data for this study was collected in a live retail environment as opposed to a laboratory setting, to achieve a higher external validity. The field time is longer than in any other comparable study (Ezeh - Harris, 2007). The above analysis provides evidence that emotions have a significant influence on spending levels in shops. The survey data for this study was collected in an international airport's retail area, and has extremely high levels of pleasure. On a 7-point scale ratings, the mean

Table 3

The effect of consumer emotions on spending (study 2)

\begin{tabular}{|c|c|c|c|c|}
\hline Hypothesis & Effect (direction) & Beta (std.) & t-value & Hyp. accepted \\
\hline H9 & Pleasure $\rightarrow$ Spending $(+)$ & .150 & $2.711^{* *}$ & yes \\
\hline H10 & Arousal $\rightarrow$ Spending $(-)$ & -.083 & $-1,502$ & no \\
\hline H11 & Dwell time $\rightarrow$ Pleasure (+) & -.023 & -.992 & no \\
\hline H12 & Dwell time $\rightarrow$ Spending $(+)$ & .126 & $2.278^{*}$ & yes \\
\hline
\end{tabular}

$\mathrm{n}=315,{ }^{*} \mathrm{p}<0.05,{ }^{* *} \mathrm{p}<0.01$ 
value for pleasure was $6.0(\mathrm{sd}=1.0)$. Previous studies have identified that the effect of pleasure on spending is stronger for pleasant retail environments then unpleasant ones (Donovan - Rossiter, 1982), and for restaurants with high entertainment elements then with for those with low entertainment elements (Kim - Moon, 2009). Therefore it is not surprising that airports are an ideal environment for high pleasure retail concepts, and the explanatory power of pleasure of total spending is higher than in comparable studies (Donovan - Rossiter, 1982). Against our expectations, however, arousal was not found to influence spending levels, although the airport environment was rated to be high arousal (on a 7 point scale mean $=4.2, \mathrm{sd}=1.3$ ). This may be explained with the concept of 'ideal level of arousal' (KroeberRiel, 1979): If arousal is too high, an unpleasant state is reached and therefore the body focuses on reducing arousal but is not ready to interact with the environment. The underlying model of environmental psychology assumes that moderate levels of arousal cause approach, and high or low arousal causes avoidance behaviour (Mehrabian - Russell, 1974). However, this raises the question why retail concepts set in high arousal environments (such as airports) can be successful, and reach very high sales levels of up to $34,000 \mathrm{USD} / \mathrm{sqm}$ annually (Rimmer, 2011). Although there have been attempts to explain retail sales in sports stadiums and amusement parks (Wakefield - Blodgett, 1999), they focus on the effects of positive emotions associated with the environment as well as service quality. It could be argued that passengers may have a certain level of anxiety caused by actual and perceived time pressure, lack of information, unfamiliarity with the environment, or fear of flying (Crawford - Melewar, 2003). At the same time, the airport causes a certain level of excitement, for example looking forward to an upcoming holiday or returning home (Torres et al., 2005). These two effects would both be considered causing arousal, and, in fact, may occur at the same time. While the first may be a more short termed anxiety, which may disappear completely once passengers have reached their departure gate, the latter could be rather a longer lasting - underlying - mood. It is therefore possible that arousal will require separation into two factors, positive and negative, and a further studies into this question have been suggested previously (Yalch - Spangenberg, 2000). While one may hypothise that positive arousal (excitement) may lead to approach type behaviours, it could be argued that also negative arousal could lead to increased levels of shop penetration and spend, depending on the shopping motivation. Customer may shop in order to distract them from anxiety or nervous emotions. Also, perceived or actual time pressure may lead to less price comparisons, and to a higher average spend per customer. Lastly, it has been suggested that possibly arousal can't even be measured using self-reporting scales, due to the time lag between the event and the interview (Groeppel-Klein, 2005). More studies of a longitudinal nature could offer further insights into this phenomenon.

A valuable contribution of this study is the link between time available for shopping ('dwell time') and sales. While time spent in a mall is rather a dependent variable, which is driven by customer needs and preferences (Levy - Weitz, 2009; Wakefield - Baker, 1998), we argue that in situations where a limited time is available for shopping, time becomes an input variable, and may influence consumer spending. In this study the time available for shopping has approximately the same effect on the spending per shopper. It is important to note that this relationship was only analysed for people who bought something, therefore it explains that people who have already decided to buy something are likely to buy more, or more expensive items, if they have more time available. Firstly shopping to "kill time" is an often cited motivation to shop at airports (Crawford - Melewar, 2003). More time available increases the likelihood to spend more. Also the (felt) lack of time leads to (perceived) time pressure, and while we could not link dwell time o arousal, one may expect time pressure to cause anxiety. This could lead to people deferring purchases (Dhar - Nowlis, 1999), avoid price comparisons (Suri - Monroe, 2003), or shop on impulse (Cobb - Hoyer, 1986). A separate study would be required to investigate this. In this study, the time spend in the retail area is considerably less $(m=13.1$ minutes, $\mathrm{sd}=11.6$ ) than the total time spent between security check and boarding $(\mathrm{m}=78.3$ minutes, $\mathrm{sd}=29.1)$, indicating that on average, passengers spend only $17 \%$ of their time available near the stores. It appears that this issue can be easily addressed by either slowing down customers when they are about to leave the zone, or to encourage them to enter earlier.

Results show that stores are associated with feelings of pleasure when they are perceived to have an attractive ambience and design. Cleanliness and tidiness, absence of noise, lighting, the special atmosphere of an airport and ease to find your way are all influencing affect. All elements of the environment are mildly correlated to one another, probably because customers are evaluating an overall experience, and are unable to differentiate exactly environmental cues. An analysis of the pearson coefficients suggest that especially lighting, easy way finding and cleanliness/tidiness have a high correlation (corr. $>.40, \mathrm{p}<.001$ ). This could be 
because customers may not have noticed any negative problems when passing through the store, and therefore gave high scores on all three items. Items such as seat availability or colour schemes may require recalling the environment, and causing a more differentiated answer. In order to understand light, cleanliness and noise, experiments with varying levels of each item may therefore lead to more accurate measures then the approach chosen here.

\section{Limitations and directions for further research}

The studies have some limitations, which also point toward future opportunities. Firstly, the measures of time available and spending were self-reported. Recalling time accurately is likely to depend on a number of personal and environmental factors, and may contain social desirability bias. It would be desirable to use actual till data for future studies. Next, there is a possibility of selfselection bias, because passengers who may have spent a long time shopping may not have had time to stop for the interviews. The difficulty of identifying a statistical relationship between arousal and consumer spending require further attention. It may be that arousal levels change while customers are at the airport, depending on events such as security screening, or perceived time pressure. Some passengers may rush to the gate first, and in this study would have reported a short dwell time and no shopping, but then relax when there is sufficient time left, and return. Therefore more longitudinal studies into variations of arousals and other relevant emotions in this environment would add valuable insights. Secondly, the studies presented here are limited to environmental effects related to ambience and design of the environment. Future studies should include social factors, such as appearance and behaviour of employees and other customers. Thirdly, further research into potential moderators should be conducted. For example experience with, and knowledge of the retail area could influence how strongly the environment changes affect.

\section{Managerial implications}

The design and ambience of high arousal, time pressured retail environments have an impact on spending levels, and therefore require the attention of operators and designers of the facility and stores. Apart from airports, findings likely to also apply to retail operations in sports stadiums, concert halls, amusement parks, harbours, ferries, train stations and trains skiing resorts and so on. The customers evaluating a retail area as pleasant attractive, and not boring are likely to spend more, therefore the appropriate design and ambience of the outlet requires the high attention, and remodelling of a store can be justified by increased future revenues. Cleanliness and tidiness, low noise levels are important. Signage and other help to find products easily are important to provide. An airport's special atmosphere has shown to increase pleasure, therefore design elements reminding customers where they are should be emphasized. The effect of the time available for shopping is equally important, therefore if practitioners should maximize customer's time available for shopping. For example, queuing delays to enter the retail area should be minimized, passenger flow out of the area should be slowed down and stores need to be located near areas which are preferred dwelling points.

\section{References}

Abelson, R.P. - Kinder, D.R. - Peters, M.D. - Fiske, S.T. (1982): Affective and Semantic Components in Political Person Perception. Journal of Personality and Social Psychology, 42: p. 619-630.

Ajzen, I. - Fishbein, M. (1977): Attitude-Behavior Relations - Theoretical-Analysis and Review of EmpiricalResearch. Psychological Bulletin, 84: p. 888-918.

Areni, C.S. - Kim, D. (1994): The influence of in-store lighting on consumers' examination of merchandise in a wine store. International Journal of Research in Marketing, 11: p. 117-125.

Babin, B.J. - Darden, W.R. (1996): Good and bad shopping vibes: spending and patronage satisfaction. Journal of Business Research, 35: p. 201-206.

Babin, B.J. - Darden, W.R. - Babin, L.A. (1998): Negative emotions in marketing research: affect or artifact? Journal of Business Research, 42: p. 271-285.

Bagozzi, R.P. - Gopinath, M. - Nyer, P.U. (1999): The role of emotions in marketing. Journal of the Academy of Marketing Science, 27: p. 184-206.

Baier, W. (2010): Das Einzelhandelsgeschaeft am Flughafen (Airport Retail Business). in: Management Circle Intensiv-Seminar. Hamburg: Hochtief AirPort

Baker, J. - Levy, M. - Grewal, D. (1992): An experimental approach to making retail store environmental decisions. Journal of Retailing, 68: p. 445-460.

Baker, J. - Parasuraman, A. - Grewal, D. - Voss, G.B. (2002): The influence of multiple store environment cues on perceived merchandise value and patronage intentions. Journal of Marketing, 66: p. 120-141.

Ballantine, P.W. - Jack, R. - Parsons, A.G. (2010): Atmospheric cues and their effect on the hedonic retail experience. International Journal of Retail - Distribution Management, 38: p. 641-653.

Baron, S. - Wass, K. (1996): Towards an understanding of airport shopping behaviour. The International Review of Retail, Distribution and Consumer Research, 6: p. 301-322. 
Bellizzi, J.A. - Crowley, A.E. - Hasty, R.W. (1983): The effects of color in store design. Journal of Retailing, 59: p. 21-47.

Bitner, M.J. (1990): Evaluating service encounters: the effects of physical surroundings and employee responses. Journal of Marketing, 54: p. 69-82.

Bitner, M.J. (1992): Servicescapes: the impact of physical surroundings on customers and employees. Journal of Marketing, 56: p. 57-71.

Bohl, P. (2013): An Investigation into Airport Related Stress, Coping and Shopping Behaviour. in: A. T. R. Society (Ed.), 17th Annual ATRS World Conference (Vol. 17, p. 12). Bergamo, Italy: ATRS

Bowes, B. (1998): The effects of emotion and time to shop on shopping - behaviour in an international airport terminal: p. 207-214.

Caldwell, C. - Hibbert, S.A. (2002): The influence of music tempo and musical preference on restaurant patrons' behavior. Psychology and Marketing, 19: p. 895-917.

Chebat, J.-C. - Michon, R. (2003): Impact of ambient odors on mall shoppers' emotions, cognition, and spending: a test of competitive causal theories. Journal of Business Research, 56: p. 529.

Chebat, J.-C. - Morrin, M. (2007): Colors and cultures: Exploring the effects of mall décor on consumer perceptions. Journal of Business Research, 60: p. 189-196.

Cheng, $Y$.- H. (2010): Exploring passenger anxiety associated with train travel. Transportation, 37: p. 875-896.

Cobb, C.J. - Hoyer, W.D. (1986): Planned versus impulse purchase behavior. Journal of Retailing, 62: p. 384-409.

Crawford, G. - Melewar, T.C. (2003): The importance of impulse purchasing behaviour in the international airport environment. Journal of Consumer Behaviour, 3: p. 85-98.

d'Astous, A. (2000): Irritating aspects of the shopping environment. Journal of Business Research, 49: p. 149-156.

Dhar, R. - Nowlis, S.M. (1999): The effect of time pressure on consumer choice deferral. Journal of Consumer Research, 25: p. 369-384.

Doganis, R. (1992): The Airport Business. London and New York: Routledge

Donovan, R.J. - Rossiter, J.R. (1982): Store atmosphere: an environmental psychology approach. Journal of Retailing, 58: p. 34-57.

Donovan, R.J. - Rossiter, J.R. - Marcoolyn, G. - Nesdale, A. (1994): Store atmosphere and purchasing behavior. Journal of Retailing, 70: p. 198-199.

Dubé, L. - Chebat, J.-C. - Morin, S. (1995): The effects of background music on consumers' desire to affiliate in buyer-seller interactions. Psychology and Marketing, 12: p. 305-319.

Ezeh, C., - Harris, L.C. (2007): Servicescape research: a review and a research agenda. Marketing Review, 7: p. 59-78.

Fodness, D. - Murray, B. (2007): Passengers' expectations of airport service quality. Journal of Services Marketing, 21: p. 492-506.
Freathy, P. - Connell, F.O. (2012): Spending time, spending money: passenger segmentation in an international airport. The International Review of Retail, Distribution and Consumer Research, 22: p. 37-41.

Freathy, P. - O'Connell, F. (2012): Spending time, spending money: passenger segmentation in an international airport. The International Review of Retail, Distribution and Consumer Research, 22: p. 397-416.

Gabor, A. - Granger, C.W.J. (1961): On the price consciousness of consumers. Journal of the Royal Statistical Society. Series C (Applied Statistics), 10: p. 170-188.

Graham, A. (2009): How important are commercial revenues to today's airports? Journal of Air Transport Management, 15: p. 106-111.

Groeppel-Klein, A. (2005): Arousal and consumer in-store behavior. Brain Res Bull, 67: p. 428-437.

Hair, J.F. - Anderson, R.E. - Tatham, R.L. - Black, W.C. (1998): Multivariate data analysis (fifth ed. ed.). Upper Saddle River, NJ.: Prentice Hall

Hasty, R.W. - Reardon, J. (1996): Retail Management. New York: McGraw Hill

Hui, M.K. - Bateson, J.E.G. (1991): Perceived control and the effects of crowding and consumer choice on the service experience. Journal of Consumer Research, 18: p. 174-184.

Hui, M.K. - Dubé, L. - Chebat, J. - C. (1997): The impact of music on consumers' reactions to waiting for services. Journal of Retailing, 73: p. 87-104.

Humphreys, I. - Francis, G. (2002): Performance measurement: a review of airports. International Journal of Transport Management, 1: p. 79-85.

Isen, A.M. (1987): Positive Affect, Cognitive-Processes, and Social-Behavior. Advances in Experimental Social Psychology, 20: p. 203-253.

Iyer, E.S. (1989): Unplanned purchasing: knowledge of shopping environment and time pressure. Journal of Retailing, 65: p. 40-57.

Izard, C.E. (2007): Basic emotions, natural kinds, emotion schemas, and a new paradigm. Perspectives on Psychological Science, 2: p. 260-280.

Józsa, L. - Bátor, A. - Sassné Grósz, A. (1999): Marketingtaktikai elemek a kiskereskedelemben (Elements of marketing tactics in retail). Marketing - menedzsment, 33: p. 19-22.

Kim, W.G. - Moon, Y.J. (2009): Customers' cognitive, emotional, and actionable response to the servicescape: A test of the moderating effect of the restaurant type. International Journal of Hospitality Management, 28: p. 144-156.

Kroeber-Riel, W. (1979): Activation Research - Psychobiological Approaches in Consumer Research. Journal of Consumer Research, 5: p. 240-250.

Levy, M. - Weitz, B.A. (2009): Retailing Management (7th ed. ed.). Boston, USA: Irwin 
Liermann, G. - Rumetsch, S. (2011): German Retail Market Property Analysis. Frankfurt: KPMG

Madeira, C. (2011): Building retail practices for the New Lisbon Airport. Airport Management, 6: p. 40-50.

Markin, R.J. - Lillis, C.M. - Narayana, C.L. (1976): SocialPsychological Significance of Store Space. Journal of Retailing, 52

Mattila, A.S. - Wirtz, J. (2001): Congruency of scent and music as a driver of in-store evaluations and behavior. Journal of Retailing, 77: p. 273-289.

Mehrabian, A. (1976): Public places and private spaces: the psychology of work, play and living environments. New York, NY: Basic Books

Mehrabian, A. - Russell, J.A. (1974): An approach to environmental psychology. Cambridge, MA.: MIT Press

Milliman, R.E. (1982): Using background music to affect the behavior of supermarket shoppers. Journal of Marketing, 46: p. 86-91.

Monroe, K.B. - Lee, A.V. (1999): Remembering Versus Knowing: Issues in Buyers' Processing of Price Information. Journal of the Academy of Marketing Science, 27: p. 207-225.

Omar, O. (2001): Airport retailing: examining airline passengers' impulsive shopping behaviour. Journal of Euromarketing, 11: p. 87-105.

Oppewal, H. - Timmermans, H. (1999): Modeling consumer perception of public space in shopping centers. Environment and Behavior, 31: p. 45-65.

Perng, S.-W. - Chow, C.-C. - Liao, W.-C. (2010): Analysis of shopping preference and satisfaction with airport retailing products. Journal of Air Transport Management, 16: p. 279-283.

Rimmer, J. (2011): The Airport Commercial Revenues Study (ACRS) 2010/11.

Rook, D.W. (1987): The buying impulse. Journal of Consumer Research, 14: p. 189-199.

Russell, J.A. - Pratt, G. (1980): A description of the affective quality attributed to environments. Journal of Personality and Social Psychology, 38: p. 311-322.

Russell, J.A. - Weiss, A. - Mendelsohn, G.a. (1989): Affect Grid: A single-item scale of pleasure and arousal. Journal of Personality and Social Psychology, 57: p. 493-502.

Soars, B. (2009): Driving sales through shoppers' sense of sound, sight, smell and touch. International Journal of Retail - Distribution Management, 37: p. 286-298.

Spangenberg, E.R. - Crowley, A.E. - Henderson, P.W. (1996): Improving the store environment: do olfactory cues affect evaluations and behaviors? Journal of Marketing, 60: p. 67-80.

Spangenberg, E.R. - Grohmann, B. - Sprott, D.E. (2005): It's beginning to smell (and sound) a lot like Christmas: the interactive effects of ambient scent and music in a retail setting. Journal of Business Research, 58: p. 1583-1589.
Spangenberg, E.R. - Sprott, D.E. - Grohmann, B. - Tracy, D. L. (2006): Gender-congruent ambient scent influences on approach and avoidance behaviors in a retail store. Journal of Business Research, 59: p. 1281-1287.

Summers, T.A. - Hebert, P.R. (2001): Shedding some light on store atmospherics - influence of illumination on consumer behavior. Journal of Business Research, 54: p. $145-150$.

Suri, R. - Monroe, K.B. (2003): The effects of time constraints on consumers' judgments of prices and products. Journal of Consumer Research, 30: p. 92-104.

Sweeney, J.C. - Wyber, F. (2002): The role of cognitions and emotions in the music-approach-avoidance behavior relationship. Journal of Services Marketing, 16: p. 51-69.

Thomas, D. (1997): Retail and leisure developments at London Gatwick Airport. Commercial Airport (British Airport Authority), 24: p. 38-41.

Thomas-Emberson, S. (2007): Airport interiors: design for business (Vol. 3). London: Wiley

Thompson, B. (2007): Airport retailing in the UK. Journal of Retail and Leisure Property, 6: p. 203-211.

Torres, E. - Dominguez, J.S. - Valdes, L. - Aza, R. (2005): Passenger waiting time in an airport and expenditure carried out in the commercial area. Journal of Air Transport Management, 11: p. 363-367.

Turley, L.W. - Milliman, R.E. (2000): Atmospheric effects on shopping behavior: a review of the experimental evidence. Journal of Business Research, 49: p. 193211.

Volkova, N. (2009): Determinants of retail revenue for today's airports. in: Berlin: The GAP research project: p. 1-19.

Wakefield, K.L. - Baker, J. (1998): Excitement at the mall: determinants and effects on shopping response. Journal of Retailing, 74: p. 515-539.

Wakefield, K.L. - Blodgett, J.G. (1999): Customer response to intangible and tangible service factors. Psychology and Marketing, 16: p. 51-68.

Wakefield, K.L. - Inman, J.J. (1993): Who are the price vigilantes? An investigation of differentiating characteristics influencing price information processing. Journal of Retailing, 69: p. 216-233.

Ward, P. - Davies, B.J. - Kooijman, D. (2007): Olfaction and the retail environment: examining the influence of ambient scent. Service Business, 1: p. 295-316.

Watson, D. - Tellegen, A. (1985): Toward a consensual structure of mood. Psychological Bulletin, 98: p. 219235.

Yalch, R.F. - Spangenberg, E.R. (1990): Effects of store music on shopping behavior. Journal of Consumer Marketing, 7: p. 55-63.

Yalch, R.F. - Spangenberg, E.R. (2000): The effects of music in a retail setting on real and perceived shopping times. Journal of Business Research, 49: p. 139-147. 